\title{
MicroRNAs in urine supernatant as potential non-invasive markers for bladder cancer detection
}

\author{
S. POSPISILOVA ${ }^{1, *}$, E. PAZOURKOVA ${ }^{2}$, A. HORINEK ${ }^{1,3}$, A. BRISUDA ${ }^{4}$, I. SVOBODOVA ${ }^{1}$, V. SOUKUP 5 , J. HRBACEK ${ }^{4}$, O. CAPOUN ${ }^{5}$, \\ T. HANUS 2 , J. MARES 6 , M. KORABECNA ${ }^{1}$, M. BABJUK ${ }^{4}$
}

${ }^{1}$ Institute of Biology and Medical Genetics, ${ }^{\text {st }}$ Faculty of Medicine, Charles University and General University Hospital in Prague, Czech Republic; ${ }^{2}$ Department of Nephrology, $1^{\text {st }}$ Faculty of Medicine, Charles University and General University Hospital in Prague, Czech Republic; ${ }^{3} 3^{\text {rd }}$ Medical Department, $1^{\text {st }}$ Faculty of Medicine, Charles University and General University Hospital in Prague, Czech Republic; ${ }^{4}$ Department of Urology, $2^{\text {nd }}$ Faculty of Medicine, Charles University and University Hospital Motol in Prague, Czech Republic; ${ }^{5}$ Department of Urology, $1^{\text {st }}$ Faculty of Medicine, Charles University and General University Hospital in Prague, Czech Republic; ${ }^{6}$ Department of Biology and Medical Genetics, Charles University in Prague, $2^{\text {nd }}$ Faculty of Medicine, Czech Republic

${ }^{\star}$ Correspondence: Sarka.Pospisilova@vfn.cz

Received April 5, 2016 / Accepted May 31, 2016

\begin{abstract}
Urinary bladder carcinoma contributes to $4 \%$ of newly diagnosed oncological diseases in the Czech Republic. Biomarkers for its early non-invasive detection are therefore highly desirable. Urine seems to be an ideal source of such biomarkers due to the content of cell-free nucleic acids, especially microRNAs (miRNAs).

To find potential biomarkers among miRNAs in urine supernatant, we examined in total 109 individuals (36 controls and 73 bladder cancer patients) in three phases. In the first - discovery - phase, microarray cards with 381 miRNAs were used for miRNA analysis of 13 controls and 46 bladder cancer patients. In the second - verification - phase, the results of this first phase were verified on the same groups of subjects by single-target qPCR assays for the selected miRNAs. For the third - validation - phase, new independent samples of urine supernatant ( 23 controls and 27 bladder cancer patients) were analyzed using single-target qPCR assays for 13 verified in the previous phase. The results of all phases were normalized to miR-191, miR-28-3p, and miR-200b, which were selected as suitable for our study by the qBase ${ }^{+\infty}$.

We found that miR-125b, miR-30b, miR-204, miR-99a, and miR-532-3p are significantly down-regulated in patients' urine supernatant. In our experiments, the analysis of miR-125 levels provided the highest AUC (0.801) with 95.65\% specificity and $59.26 \%$ sensitivity, the analysis of miR-99a lead to AUC (0.738) with $82.61 \%$ specificity and $74.07 \%$ sensitivity.

We demonstrate that levels of these miRNAs could potentially serve as promising diagnostic markers for the non-invasive diagnostics of bladder cancer.
\end{abstract}

Key words: bladder cancer, urine supernatant, microRNA, non-invasive marker, diagnostic marker

MicroRNAs (miRNAs) are 21-28 nucleotides long RNAs, which block the process of translation by mechanisms based on their complementarity with target mRNAs [1]. miRNAs were discovered by Lee et al. [2] in 1993 in Caenorhabditis elegans. They are found in most body fluids, often enclosed in exosomes [3]. miRNAs as small noncoding regulatory RNA molecules participate not only in many physiological processes, but they are involved also in different pathways included in pathogenesis of broad spectrum of diseases [4]. In some cases, alteration of particular miRNAs expression indicates the presence of pathological changes even before their clinical manifestation [5]. Some miRNAs are tissue specific while others are ubiquitous [6]. Numerous target genes regulated by miRNAs are known [7-10], however, many regulatory relationships remain undiscovered.

Bladder carcinoma belongs to the most common urooncological diseases. It is the sixth most often diagnosed oncological disease and it makes up $4 \%$ of newly diagnosed cancers in the Czech Republic [11]. Approximately $70 \%$ of bladder cancers are represented by non-invasive tumors in stage Ta with a very good prognosis despite numerous relapses. The remaining tumors are invasive with infiltration into sub-epithelial connective tissues and muscles (stages T1-T4). Molecular differences were found in these two types 
of tumors [12], including altered miRNAs expression [13]. Five year stage-specific survival is between $8.1 \%$ and $90.8 \%$, according to a recent large Surveillance, Epidemiology and End Results analysis [14].

The incidence of bladder cancer and the mortality rate was 20.33 cases and 7.63 cases, respectively, per 100,000 inhabitants in the Czech Republic in 2013. The incidence shows a decreasing tendency since 2004 but mortality stays at the same level. Bladder cancer is three times more frequent in men than in women [15]. The application of methods for its early detection could contribute to decreased mortality rate of this disease. Currently, the one and only reliable examination is cystoscopy [16], an invasive and uncomfortable procedure with corresponding risks. Therefore, one of the priorities of medical research is finding the appropriate early non-invasive marker(s) for the early detection of bladder cancer. The studies focused on the search for such miRNA markers are listed in Supplement 1.

Some studies tested only the tumor tissue to reveal miRNAs signatures in bladder cancer. For example Lin et al. [17] found that many miRNAs are deregulated in tumor tissue. Among others, the most significant down-regulation of miR-143 and miR-125b was detected. The authors found that the growth was inhibited in cell lines transfected with miR-143. This finding confirmed the theory that miR-143 may act as a tumor suppressor. Zhang et al. [18] analyzed miRNA composition in bladder tissue. They revealed six down-regulated miRNAs (miR-1, miR-99a, miR-125b, miR-133a, miR-133b and miR$143)$ in cancer tissues.

The comparison of the results obtained on tumor and control tissues may serve as a serious background for the urine analysis. The examination of patients' urine seems to be the most promising strategy for the development of the non-invasive early diagnostics.

Some studies focused on miRNAs in urine supernatant. Zhang et al. [18] also evaluated the urine supernatant and found four down-regulated miRNAs (miR-99a, miR-125b, miR-133b and miR-143). They proposed miR-99a and miR$125 \mathrm{~b}$ as a non-invasive marker, whose concentration were significantly lower in the patients' urine and showed a correlation with a tumor grade. These two miRNAs returned to normal levels four weeks after a surgery. Snowdown et al. [19] confirmed decreased miR-125b levels in cancer patients' urine supernatant. Yun et al. [16] found miR-145 and miR-200a as bladder cancer markers - miR-145 levels were significantly lowered in patients' urine supernatant compared to control samples and they correlated with the cancer grade. The down-regulated miR-200a indicated a higher risk of recurrence in lower tumor grades in this study.

Zhou et al. [20] discovered that levels of miR-106b are increased in bladder cancer patients' urine supernatant. This miRNA belongs to miR-106b-25 cluster, which is often up-regulated in cancers $[21,22]$. Higher levels of urinary miR-106b were detected in patients with invasive diseases, and were significantly reduced 14 days after surgery [20]. Kim et al. [23] examined miR-214 which was up-regulated in patients with bladder cancer. The patients with recurrence had lower levels of miR-214 in urine supernatant compared to the patients without it.

Other studies focused on the whole urine. Hanke et al. [24] revealed that the miR-126/miR-152 ratio can detect bladder cancer in the whole urine. Yamada et al. [25] found that miR-96 and miR-183 are up-regulated in the whole urine of bladder cancer patients; these miRNAs had higher level in higher tumor stages.

All studies mentioned above and summarized in Supplement 1 suggest that a realistic possibility to detect alterations in miRNA levels in urine supernatant exists and that it could be further explored as a non-invasive diagnostic procedure for bladder cancer detection. Therefore, we decided to test the levels of a broad panel of miRNAs in urine supernatant of Czech bladder cancer patients and corresponding control samples, then to verify and validate the results and to propose a potential non-invasive diagnostic strategy.

\section{Patients and methods}

Patients and samples. With the written consent of the patients and with the approval of the local Ethic committee, samples of naturally voided urine were collected during the period 5/2012 - 6/2015 from 109 individuals recruited at the Department of Urology, ${ }^{\text {st }}$ Faculty of Medicine, Charles University in Prague, and General University Hospital in Prague, and the Department of Urology, $2^{\text {nd }}$ Faculty of Medicine, Charles University in Prague, and University Hospital Motol in Prague, Czech Republic. Patients with positive urine culture and/or leukocyturia were excluded from the study. The second morning urine, i.e. approximately 2 hours after the first morning urine [26], was analyzed from each subject.

$50 \mathrm{ml}$ of urine samples were collected in a tube with $1.5 \mathrm{ml}$ RNAlater (Ambion, Life Technologies, NY, USA) and centrifuged at $4000 \mathrm{rpm}$ for $10 \mathrm{~min}$ at $10^{\circ} \mathrm{C}$. The supernatant was frozen at $-20^{\circ} \mathrm{C}$.

Patients with known or suspected bladder cancer underwent transurethral resection of the bladder or radical cystectomy and stages with grades were verified by pathologists. The WHO 2004 grading system was used. All tumors were urothelial carcinomas.

The study consists of three parts:

In the first part of the study (the discovery phase), 59 individuals ( 46 of them with bladder cancer and 13 healthy volunteers) were examined using array technique. Clinical characteristics of examined subjects are summarized in Table 1.

In the second phase (the verification phase), the same groups of individuals as in the discovery phase were examined. Only the miRNAs selected in the first part of the study were analyzed using the second part of stored urine supernatant and single-target qPCR assays. 
Table 1. Clinical characteristics of subjects examined in the first and the second part of the study

\begin{tabular}{|c|c|c|c|c|c|c|c|c|}
\hline & $\mathbf{N}$ & $\begin{array}{c}\text { Age range } \\
\text { (mean) }\end{array}$ & Male & Female & & Subgroups & & $\mathbf{N}$ \\
\hline Controls & 13 & $\begin{array}{l}29-80 \\
(54.8)\end{array}$ & 8 & 5 & & HEALTHY group & & 13 \\
\hline \multirow[t]{6}{*}{ Patients } & 46 & $\begin{array}{l}41-86 \\
(67.9)\end{array}$ & 32 & 14 & & LG & $\mathrm{HG}$ & \\
\hline & & & & & $\mathrm{pTa}$ & 8 & 0 & 8 \\
\hline & & & & & pT1 & 7 & 7 & 14 \\
\hline & & & & & pT2 & 0 & 9 & 9 \\
\hline & & & & & pT3 & 0 & 8 & 8 \\
\hline & & & & & pT4 & 0 & 7 & 7 \\
\hline
\end{tabular}

Table 2. Clinical characteristics of subjects examined in the third part of the study

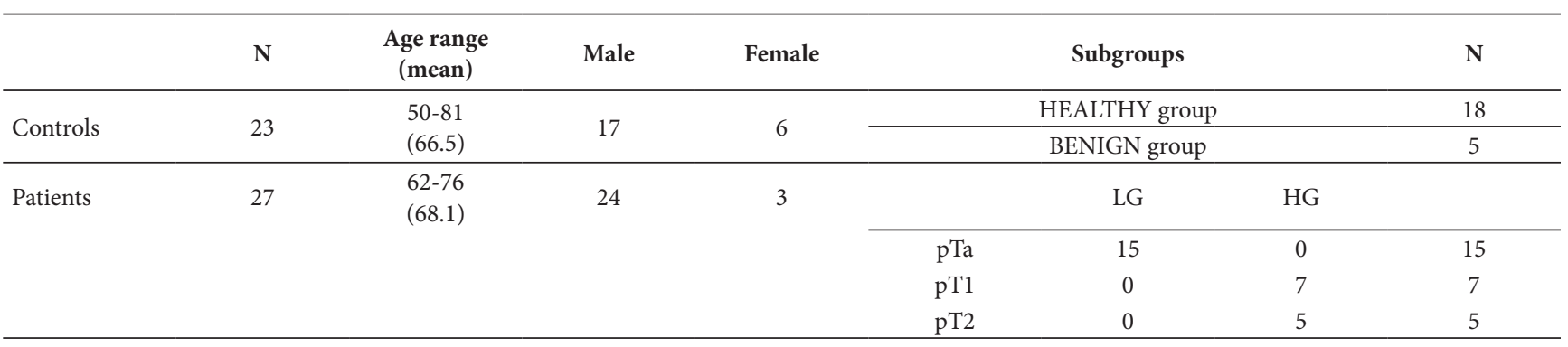

For the third part of the study (the validation phase), 50 new individuals were analyzed ( 27 patients with bladder cancer and 23 controls - clinical characteristics are given in Table 2). Thirteen miRNAs selected in the previous parts of the study were examined using single-target qPCR assays.

Isolation of miRNAs. In all three parts of the study, identical protocol for miRNAs isolation was employed. Collected samples were thawed at room temperature and $1 \mathrm{ml}$ of urine supernatant was used for isolation of circulating miRNAs by the Urine microRNA Purification Kit (NORGEN BIOTEK CORPORATION, Canada) in accord with the recommendation of the manufacturer.

The purified miRNAs were immediately used for reverse transcription.

Reverse transcription. For the discovery part of the study, reverse transcription was performed in accord with the protocol of TaqMan MicroRNA Reverse Transcription Kit with the Megaplex ${ }^{\mathrm{TM}}$ RT Primers, Human Pool A v2.1 (Applied Biosystems $^{\mathrm{TM}}$, CA, USA). Reverse transcription was carried out in the Veriti ${ }^{\oplus}$ Thermal Cycler (Applied Biosystems ${ }^{\mathrm{TM}}$, Germany).

For the second and the third part of the study, reverse transcription was done in accord with the protocol of TaqMan ${ }^{\circ}$ MicroRNA Reverse Transcription Kit with TaqMan ${ }^{\circledast}$ MicroRNA Assays (Applied Biosystems ${ }^{\mathrm{TM}}$, CA, USA) in the Veriti ${ }^{\circ}$ Thermal Cycler (Applied Biosystems ${ }^{\mathrm{TM}}$, Germany).

The cDNAs were frozen at $-20^{\circ} \mathrm{C}$ immediately.
Preamplification. The preamplification step was used only in the first part of the study. After thawing on ice, the cDNAs were preamplified in accord with the protocol of TaqMan ${ }^{\infty}$ MicroRNA Preamplification with the Megaplex ${ }^{\mathrm{TM}}$ PreAmp Primers, Human Pool A v2.1 (Applied Biosystems ${ }^{\mathrm{TM}}$, CA, USA) in the Veriti ${ }^{\circledast}$ Thermal Cycler (Applied Biosystems ${ }^{\mathrm{TM}}$, Germany). The samples were frozen at $-20^{\circ} \mathrm{C}$ immediately without any dilution steps.

Analysis of miRNAs in arrays. In the discovery part of the study, after thawing on ice the preamplified samples were loaded on to the TaqMan ${ }^{\circ}$ Array Human MicroRNA Card A v.2.1 (Applied Biosystems ${ }^{\mathrm{TM}}$, CA, USA).

The Array cards were run on the 7900HT Fast Real Time PCR System (Applied Biosystems ${ }^{\mathrm{TM}}$, CA, USA).

Analysis of miRNAs using single-target qPCR assays. In the second and the third part of the study, single TaqMan $^{\oplus}$ MicroRNA Assays (Applied Biosystems ${ }^{\mathrm{TM}}$, CA, USA) were used. Amplification reactions were performed in $14 \mu \mathrm{l}$ of total volume containing $3.2 \mu \mathrm{l}$ of nuclease-free water for injection (Fresenius Kabi, Czech Republic), $8 \mu$ l of TaqMan ${ }^{\circ}$ UNIVERSAL MasterMix II, no UNG (Applied Biosystems ${ }^{\mathrm{TM}}$, CA, USA), $0.8 \mu$ l of TaqMan ${ }^{\circledR}$ MicroRNA Assay (Applied Biosystems $^{\mathrm{TM}}$, CA, USA) and $4 \mu \mathrm{l}$ of cDNA.

The plates with assays were run on the 7900HT Fast Real Time PCR System (Applied Biosystems ${ }^{\mathrm{TM}}$, CA, USA).

Statistical analysis. Results were processed in ExpressionSuite Software v1.0.3 (Applied Biosystems ${ }^{\mathrm{TM}}$, CA, USA), 
$\mathrm{qBase}^{+\oplus}$ v2.4 (Biogazelle, Belgium), Statistica software version 10 (StatSoft, Inc., Tulsa, USA) and software $\mathrm{G}^{\star}$ Power version 3.1.9.2 (Franz Faul, Universität Kiel, Germany).

Three miRNAs (miR-191, miR-28-3p and miR-200b), chosen by the geNorm analysis within the $\mathrm{qBase}^{+\oplus}$ program v2.4 (Biogazelle, Belgium), were used for the normalization of the expression rates for all parts of the study.

Man-Whitney's U test with the Benjamini-Hochberg correction was used for statistical analysis of the data.

The $\mathrm{G}^{*}$ Power software was used for determination of the effective size of compared groups. The analysis was based on the data from the second phase of the study. The determined effective size was used for the determination of sample size of each group in the third phase of the study. The power analysis was computed for Mann-Whitney test which was used for testing of miRNA expressions in patient and control groups in the third phase of the study.

Decision tree was constructed in order to evaluate the diagnostic power of miRNAs selected in the validation phase. We used alternating decision tree with the boosting methods. The Waikato Environment for Knowledge Analysis (Weka) software the (University of Waikato, New Zealand) was used for this purpose.

Bioinformatics analysis. We performed the search for validated targets of selected miRNAs using the miRWalk database [27]. The selected gene sets were analyzed using the Database for Annotation, Visualization and, Integrated Discovery (DAVID) $[28,29]$ by the functional annotation clustering with medium classification stringency and with Benjamini correction calculations.

Table 3. Results of array experiments (the discovery phase), p-values obtained after two different normalization methods (Mann-Whitney tests with Benjamini-Hochberg correction)

\begin{tabular}{lcccc}
\hline \multirow{2}{*}{ miRNA } & $\begin{array}{c}\text { Data normalized } \\
\text { to the mean of selected } \\
\text { normalizers (miR-191, } \\
\text { miR-28-3p and miR-200b) }\end{array}$ & $\begin{array}{c}\text { Data normalized to global } \\
\text { mean }\end{array}$ \\
\cline { 2 - 5 } p-value & $\begin{array}{c}\text { Fold Change } \\
\text { (controls vs. } \\
\text { patients) }\end{array}$ & p-value & $\begin{array}{c}\text { Fold Change } \\
\text { (controls vs. } \\
\text { patients) }\end{array}$ \\
\hline miR-99a & 0.0001 & 12.51 & 0.0069 & 4.30 \\
let-7c & 0.0002 & 8.02 & 0.0157 & 2.76 \\
miR-125b & 0.0003 & 14.71 & 0.0085 & 5.06 \\
miR-532-3p & 0.0008 & 7.49 & 0.0221 & 2.58 \\
miR-30b & 0.0009 & 6.34 & 0.0476 & 2.18 \\
miR-16 & 0.0011 & 0.17 & 0.0004 & 0.06 \\
miR-204 & 0.0021 & 8.85 & 0.0375 & 3.04 \\
miR-425 & 0.0042 & 0.14 & 0.0015 & 0.05 \\
miR-93 & 0.0388 & 0.46 & 0.0015 & 0.18 \\
miR-372 & 0.1968 & 0.04 & 0.1455 & 0.02 \\
miR-519a & 0.3395 & 0.25 & 0.1339 & 0.11 \\
miR-301a & 0.4106 & 0.57 & 0.0520 & 0.25 \\
miR-199a-3p & 0.5229 & 0.21 & 0.1192 & 0.09 \\
\hline
\end{tabular}

\section{Results}

Discovery phase. In the first - discovery - phase we examined 381 miRNAs at all. We aimed to test a large amount of miRNAs and to select the most promising ones for further analysis. Simultaneously, we tried to find the most suitable miRNAs, which would be useful for normalization purposes when working with urine supernatant. Three miRNAs (miR-191, miR-28-3p and miR-200b) were chosen as the normalizers by the geNorm analysis within the $\mathrm{qBase}^{+\oplus}$ program v2.4 (Biogazelle, Belgium).

For data analysis we applied two normalization methods: the normalization to the mean of selected miRNAs (miR-191, miR-28-3p and miR-200b) and the normalization to the global mean on all data sets. We compared the patients' results with the healthy peoples' using Mann-Whitney tests with Benjamini-Hochberg corrections. The results of the first part of the study are summarized in Table 3.

Verification phase. In the second - verification - phase, 13 miRNAs were selected from the discovery phase for testing. The selection of miRNAs was based on the lowest p-values associated with the high difference between controls and patients (expressed in the form of Fold Change), determined independently by both normalization methods (Table 3 ).

The verification part of the study served for the confirmation of the results obtained in the discovery phase. In contrast to the discovery phase, which was based on the array technology, we employed single-target qPCR assays in this one. For this purpose, miRNAs were isolated using the second part of stored urine supernatant and the normalization to the three selected miRNA normalizers (miRNAs miR-191, miR-28-3p and miR-200b) was used. We confirmed statistically significant differences between controls and patients in 10 out of 13 miRNAs tested (Table 4, Figure 1).

Several classification views are used in the bladder cancer diagnostics: non-muscle invasive bladder cancer (NMIBC) and muscle invasive bladder cancer (MIBC) classifications are important for the choice of the treatment strategy; tumor

Table 4. Results of the second - verification - phase of the study based on single-target assays.

\begin{tabular}{lcc}
\hline miRNA & p-value & $\begin{array}{c}\text { Fold Change } \\
\text { (controls vs. patients) }\end{array}$ \\
\hline miR-125b & $<0.0001$ & 11.77 \\
let-7c & $<0.0001$ & 9.18 \\
miR-204 & 0.0002 & 7.99 \\
miR-16 & 0.0002 & 0.23 \\
miR-532-3p & 0.0002 & 3.19 \\
miR-425 & 0.0002 & 0.42 \\
miR-30b & 0.0005 & 3.60 \\
miR-99a & 0.0006 & 6.09 \\
miR-93 & 0.0006 & 0.54 \\
miR-199a-3p & 0.0060 & 0.30 \\
\hline
\end{tabular}




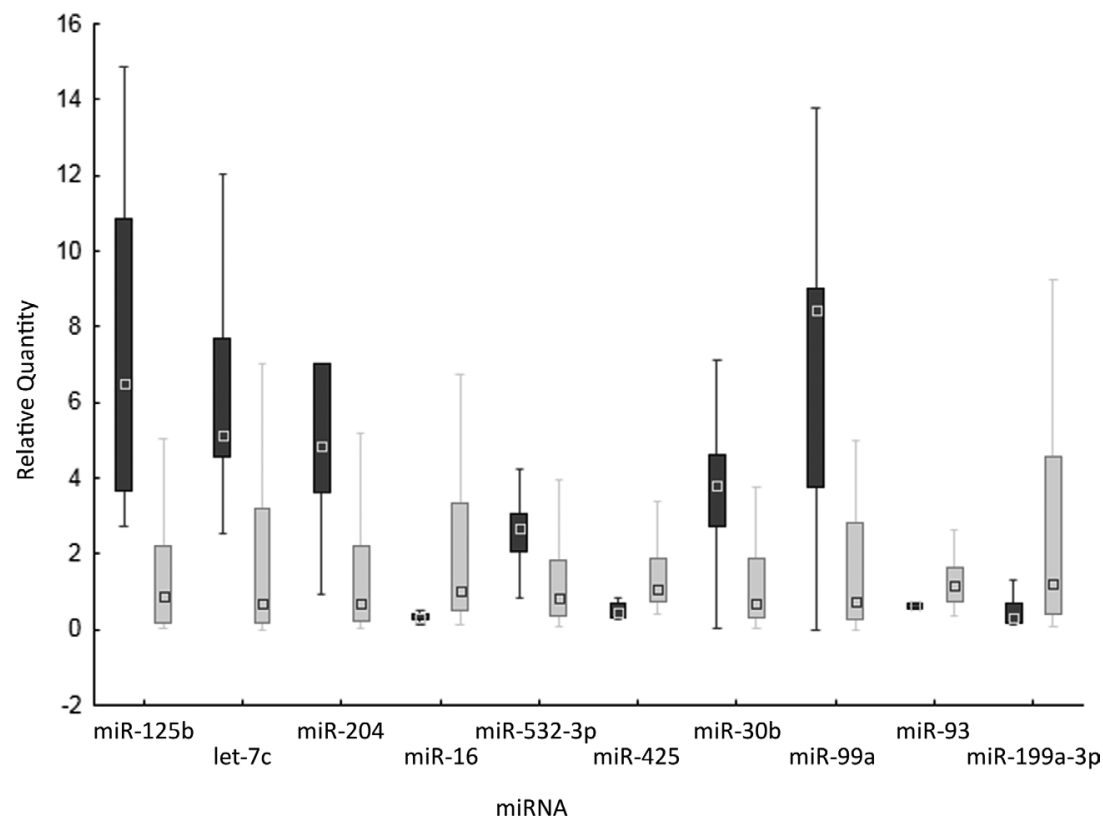

Figure 1. Boxplots illustrating the results obtained in the verification phase. Medians given by squares, $25^{\text {th }}$ and $75^{\text {th }}$ percentiles given by rectangles. Dark grey columns $=$ control subjects, light gray columns $=$ bladder cancer patients

stages Ta-T4 show biological characteristics; low grade (LG) and high grade $(\mathrm{HG})$ show the differentiation of tumor and are also important for the treatment choice especially in the lower tumor stages. We decided to test the distribution of patients in NMIBC (pTa and pT1, 22 patients) and MIBC (pT2-pT4, 24 patients) against controls. Groups were compared by Kruskal-Wallis ANOVA test. Statistically significant differences were observed among controls and both groups of patients. There is one exception: miR-199a-3p which is statistically significant only among controls and MIBC. There are no differences among groups of patients. The results are shown in Table 5, Figure 2.

Validation phase. In the third - validation - part of the study, we aimed to validate the results of the previous phase on a new cohort of patients and controls. The same normalization procedure as in the verification phase was used. Power analysis was performed, using the data from the second phase, to determine the effective size of compared groups. We considered the miRNAs from Table 6 in the third phase of the study. The power analysis determined the minimum sample size in the interval of $7-21$ individuals in both groups for all the miRNAs. The expressions in the patients' group were at least two times higher than the expressions in the control group for all the considered miRNAs. Thus, the sample size of dataset in the third phase ( 23 controls and 27 patients) is sufficient for the analysis as defined in the methodology. Among control subjects, the patients with benign urological diseases were also included, to simulate the real clinical situation (Table 2). Using these new sets of samples, we confirmed significant differences in miRNAs levels between controls and patients in five miRNAs: miR-125b, miR-30b, miR-204, miR-99a, and miR-532-3p. All these miRNAs were down-regulated in patients' urine supernatant. The results are summarized in Table 6 . The boxplots illustrating these results are shown in Figure 3.

Due to the findings of correlation between miR-99a and miR-125b levels $(r=0.89$, $p$-value $<0.0001)$, we performed the bioinformatics analysis of validated targets of these miRNAs and the potential roles of these targets in cell cycle regulation and tumor growth. The most significant results of this analysis are listed in Table 7 . The results suggest that both miRNAs are able to regulate large sets of genes included in

Table 5. Results of the second - verification - phase of the study based on the distribution of patients to NMIBC and MIBC

\begin{tabular}{lccc}
\hline & \multicolumn{3}{c}{-value } \\
\hline & $\begin{array}{c}\text { Controls vs. } \\
\text { NMIBC }\end{array}$ & $\begin{array}{c}\text { Controls vs. } \\
\text { MIBC }\end{array}$ & $\begin{array}{c}\text { NMIBC vs. } \\
\text { MIBC }\end{array}$ \\
\hline miR-125b & 0.0015 & $<0.0001$ & 0.4530 \\
let-7c & 0.0032 & $<0.0001$ & 0.3626 \\
miR-204 & 0.0020 & 0.0002 & 1 \\
miR-16 & 0.0203 & $<0.0001$ & 0.1429 \\
miR-532-3p & 0.0051 & 0.0003 & 1 \\
miR-425 & 0.0198 & $<0.0001$ & 0.2107 \\
miR-30b & 0.0454 & 0.0001 & 0.1853 \\
miR-99a & 0.0154 & 0.0009 & 1 \\
miR-93 & 0.0475 & 0.0003 & 0.2782 \\
miR-199a-3p & 0.3833 & 0.0012 & 0.0607 \\
\hline
\end{tabular}




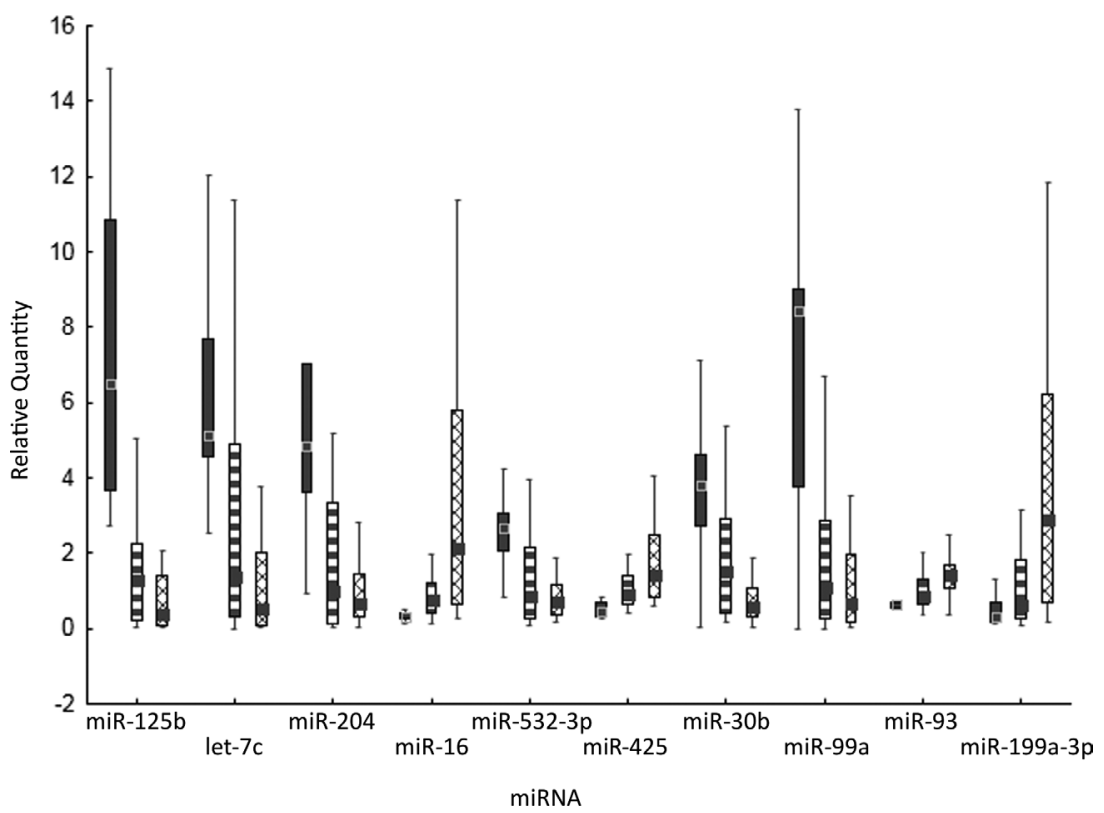

Figure 2. Boxplots illustrating the results of the verification phase based on the distribution of patients to NMIBC and MIBC. Medians given by squares, $25^{\text {th }}$ and $75^{\text {th }}$ percentiles given by rectangles. Dark grey columns $=$ control subjects, striped columns $=$ NMIBC, squared columns $=$ MIBC.

pathways crucial for tumor development, especially in the bladder cancer.

For the potential development of a practically useful diagnostic strategy, we listed the values of sensitivity, specificity and AUC achieved in the third part of our study in Table 6. The best decision tree obtained by the software Weka (University of Waikato, New Zealand) was based on combined analysis of miR-125b, miR-204, miR-5323p and miR-99a and achieved $\mathrm{AUC}=0.836$, sensitivity $80 \%$ and specificity $71 \%$.

All our datasets contained information about the stages of bladder cancer in examined patients. However, the power analysis determined the sample size as too high for a reliable testing of differences in the miRNA levels between stages. Therefore, our analysis was focused predominantly on the effective differentiation between patients and controls. In the validation phase, no patients with stages pT3 and pT4 were included, in order to test the ability of the method to detect patients with lower bladder cancer stages.

\section{Discussion}

In miRNA studies, there are no generally accepted endogenous controls as normalizers for different tissues and body fluids, but the process of data normalization is fundamental and it is known that it can highly alter the results of the study. We did not use the commonly employed endogenous controls as U6 or RNU6B because these small nuclear RNAs are not suitable for normalization purposes neither in all tissues [30] nor in all body fluids. [31]. Ratert et al. [32] also recommend the use of other endogenous controls than these small nuclear RNAs, even for the study of bladder cancer tissues. As there is no study aiming to find appropriate endogenous controls in urine supernatant for the purposes of miRNA studies, we decided to rely on the geNorm analysis within the $\mathrm{qBase}^{+\odot}$ program v2.4 (Biogazelle, Belgium) as a widely used tool searching for the normalizers [33]. Three miRNAs (miR-191, miR-28-3p and miR-200b) were selected by this algorithm.

Table 6. Results of the third - validation - phase.

\begin{tabular}{|c|c|c|c|c|c|c|}
\hline & p-value & $\begin{array}{l}\text { Fold Change (con- } \\
\text { trols vs. patients) }\end{array}$ & $\begin{array}{c}\text { Sensitivity } \\
(\%)\end{array}$ & $\begin{array}{c}\text { Specificity } \\
(\%)\end{array}$ & AUC & Cut-off value \\
\hline miR-125b & $<0.0001$ & 3.50 & 59.26 & 95.65 & 0.801 & $\leq 0.618$ \\
\hline miR-204 & 0.0001 & 3.00 & 53.85 & 100.00 & 0.771 & $\leq 0.703$ \\
\hline miR-99a & 0.0019 & 2.67 & 74.07 & 82.61 & 0.738 & $\leq 1.003$ \\
\hline miR-30b & 0.0002 & 2.10 & 66.67 & 82.61 & 0.760 & $\leq 1.115$ \\
\hline miR-532-3p & 0.0031 & 1.64 & 59.26 & 86.96 & 0.718 & $\leq 1.002$ \\
\hline
\end{tabular}




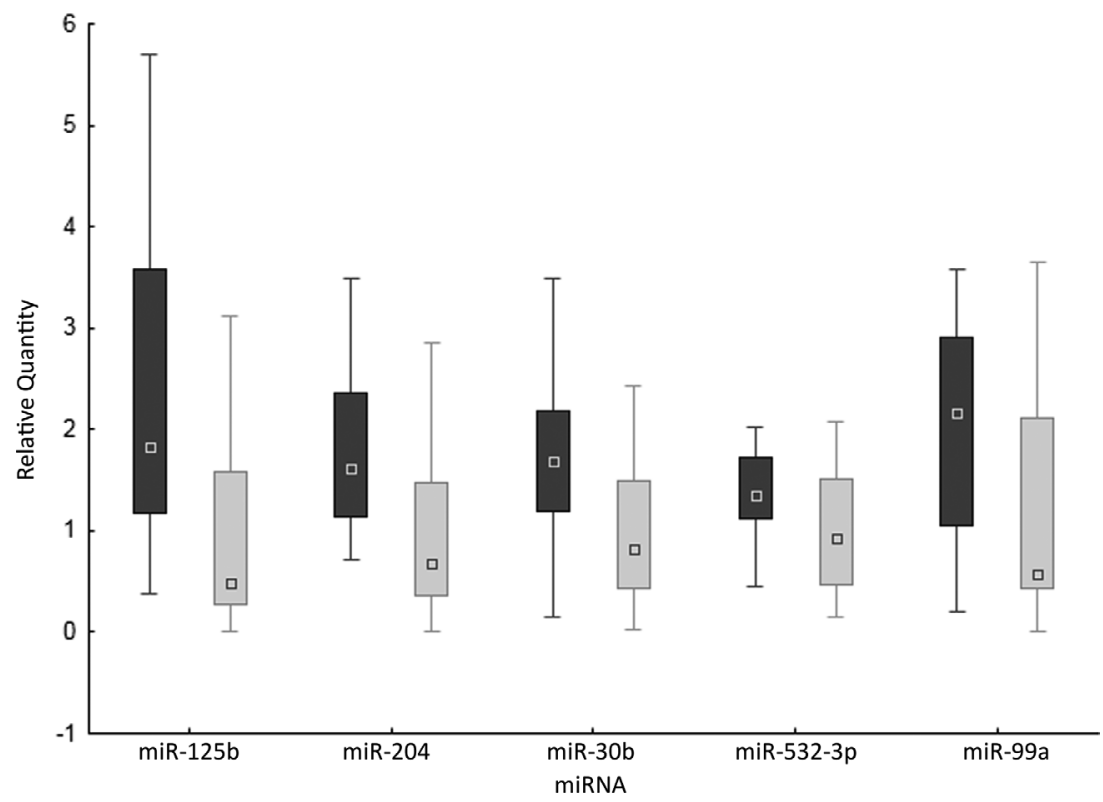

Figure 3. Boxplots illustrating the results obtained in validation phase. Medians given by squares, $25^{\text {th }}$ and $75^{\text {th }}$ percentiles given by rectangles. Dark grey columns $=$ control subjects, light gray columns = bladder cancer patients.

For the discovery phase of our study, the array technology was used to obtain the pilot data which were verified using the single-target qPCR reactions. Then the data were validated on the independent sets of samples, whose size was determined with regard to the results of the power analysis.

Using this approach, we determined five miRNAs with significantly decreased levels in urine supernatant of bladder cancer patients compared to controls: miR-125b, miR-204, miR-99a, miR-30b, and miR-532-3p.

Our results are in partial agreement with the results of previous studies listed in Supplement 1, namely with regard to the decreased levels of miR-99a and miR-125b, found in urine supernatant $[18,19]$. The partial overlap among different studies may be regarded as the consequence of applications of the broad spectrum of methodological approaches by different researchers [33]. Due to this variability of methodological strategies, the confirmatory results among various studies may represent the findings with the real biological significance.

Previous studies found the decreased levels of miR-125b and miR-99a not only in patient's bladder cancer tissue [17, $18,34]$ in comparison with normal tissue, but also in urine supernatant $[18,19]$.

The functions of miR-125b in bladder cancer were studied using transfection experiments. After transfection of miR-125b in bladder cancer cell lines, the cell growth was significantly inhibited in comparison to controls. The authors found also a potential target of miR-125b - an oncogene E2F3. The translation of this protein was inhibited by miR-125b [35].

The down-regulation of miR-99a was detected by Feng's team in bladder cancer cell lines, cancer tissue and plasma of the bladder cancer patients [36]. The genes for both above

Table 7. Selected top terms identified by DAVID for 256 genes regulated either by miR-99a or by miR-125b

\begin{tabular}{lcc}
\hline Term & p-value after Benjamini correction & Number of genes \\
\hline Regulation of apoptosis & $1.8 \times 10^{-22}$ & 64 \\
Regulation of transcription from RNA polymerase II & $6.5 \times 10^{-23}$ & 62 \\
Response to organic substance & $1.4 \times 10^{-16}$ & 52 \\
Response to steroid hormone stimulus & $1.9 \times 10^{-13}$ & 26 \\
Response to organic cyclic substance & $3.5 \times 10^{-6}$ & 14 \\
Regulation of DNA binding & $1.2 \times 10^{-13}$ & 22 \\
Bladder cancer & $4.3 \times 10^{-11}$ & 15 \\
Blood vessel development & $2.2 \times 10^{-5}$ & 18 \\
\hline
\end{tabular}


discussed down-regulated miRNAs (miR-125b and miR-99a) are localized together in the cluster on chromosome 21 [37]. We found the correlation between their levels in bladder cancer patients and controls $(\mathrm{r}=0.89$, $\mathrm{p}$-value $<0.0001)$. Bioinformatics analysis of validated targets of both miRNAs revealed the set of genes, which are included in pathways relevant for bladder cancer development. The finding of 52 genes included in the "Response to organic substances" and 14 genes included especially in "Response to organic cyclic substances" may be of special interest with regard to smoking as the important risk factor for the bladder cancer development [38]. According to these findings we tried to interpret our data with regard to the smoking behavior of examined subjects, but after a critical revision of the group sizes (non-smokers, ex-smokers and smokers), we realized that our sets are not suitable for this type of analysis due to their limited sizes and clinical heterogeneity. The further research focused on this complex regulatory network containing miR-99a and miR-125b may provide better understanding of the roles of these two miRNAs in the bladder cancerogenesis.

According to the fact that bladder cancer is more frequent in men [15], we tested differences in miRNAs expression patterns among men and women. We didn't find any statistically significant differences in expression of miRNAs examined in our study.

The down-regulation of miR-204 was found in bladder cancer cell lines [39, 40], bladder cancer tissues [13, 40], and in urine sediment [40] of bladder cancer patients (Supplement 1), but the levels of this miRNA has not been analyzed in the urine supernatant yet.

The studies performed till today provided inconsistent results regarding the altered levels of miR-30b in bladder cancer patients. Wszolek et al. [41] confirmed down-regulation of miR-30b in bladder cancer tissue but in invasive compared to non-invasive tumors, other studies written by the same team of authors described up-regulation of miR-30b in tumor tissue [42, 43] (Supplement 1).

Another study didn't show a significant difference in levels of miR-30b in whole urine in patients with bladder cancer and in healthy controls [44].

No study describing the altered expression of miR-532-3p in bladder cancer was published, according to our knowledge. This miRNA was found as up-regulated in esophageal cancer tissue [45].

The comparison of AUC values, sensitivities and specificities for miRNAs selected in the validation phase (Table 6) with the performance of tests based on cytology suggests that the analysis of these selected miRNAs in urine supernatant may potentially enrich the portfolio of non-invasive tests for bladder cancer detection. Urine cytology nowadays represents the only routinely used clinical test. Its diagnostic performance is very good in high grade cancer (sensitivity of $86.5 \%$ and specificity of $92.6 \%$ ), but poor in low grade tumors (sensitivity of $38.5 \%$ and specificity of $92.6 \%$ ) [26]. A combination of the novel markers with cytology may be the future prospect.
Our results suggest that we found a set of biologically relevant miRNA markers (miR-125b, miR-204, miR-99a, miR-30b and miR-532-3p) with the down-regulated levels in urine supernatant in patients with bladder cancer. The sensitivity, specificity, and AUC values, especially for miR-125b, belong to the best ones reported till today, with respect to the performance of a biomarker for non-invasive bladder cancer detection [26].

The findings of our study are promising. After elaboration of a user-friendly laboratory protocol and after validation on larger cohorts of control subjects and patients with different bladder cancer stages, the reported approach could be applied routinely for non-invasive detection of bladder cancer patients.

Acknowledgements: The study was supported by the grant no. IGA NT12417 of the Internal Grant Agency of the Ministry of Health of the Czech Republic.

Supplementary information is available in the online version of the paper.

\section{References}

[1] Wightman B, HA I, RUVKUN G. Posttranscriptional regulation of the heterochronic gene lin-14 by lin- 4 mediates temporal pattern formation in C. elegans. Cell 1993; 75: 855-862. http://dx.doi.org/10.1016/0092-8674(93)90530-4

[2] LEE RC, FEINBAUM RL, AMBROS V. The C. elegans heterochronic gene lin-4 encodes small RNAs with antisense complementarity to lin-14. Cell 1993; 75: 843-854. http:// dx.doi.org/10.1016/0092-8674(93)90529-Y

[3] GALLO A, TANDON M, ALEVIZOS I, ILLEI GG. The majority of microRNAs detectable in serum and saliva is concentrated in exosomes. PloS One 2012; 7: e30679. http:// dx.doi.org/10.1371/journal.pone.0030679

[4] AMBROS V. microRNAs: tiny regulators with great potential. Cell 2001; 107: 823-826. http://dx.doi.org/10.1016/S00928674(01)00616-X

[5] HROMADNIKOVA I, KOTLABOVA K, DOUCHA J, DLOUHA K, KROFTA L. Absolute and Relative Quantification of Placenta-Specific MicroRNAs in Maternal Circulation with Placental Insufficiency-Related Complications. J Mol Diagn 2012; 14: 160-167. http://dx.doi. org/10.1016/j.jmoldx.2011.11.003

[6] LAGOS-QUINTANA M, RAUHUT R, MEYER J, BORKHARDT A, TUSCHL T. New microRNAs from mouse and human. RNA 2003; 9: 175-179. http://dx.doi. org/10.1261/rna.2146903

[7] UCAR A, GUPTA SK, FIEDLER J, ERIKCI E, KARDASINSKI $\mathrm{M}$ et al. The miRNA-212/132 family regulates both cardiac hypertrophy and cardiomyocyte autophagy. Nat Commun 2012; 3: 1078. http://dx.doi.org/10.1038/ncomms2090

[8] CALLEGARI E, ELAMIN BK, SABBIONI S, GRAMANTIERI L, NEGRINI M. Role of microRNAs in hepatocellular carcinoma: a clinical perspective. Onco Targets Ther 2013; 6: 1167-1178. 
[9] ROTTIERS V, NÄÄR AM. MicroRNAs in metabolism and metabolic disorders. Nat Rev Mol Cell Biol 2012; 13: 239-250. http://dx.doi.org/10.1038/nrm3313

[10] MURRI M, INSENSER M, FERNANDEZ-DURAN E, SAN-MILLAN JL, ESCOBAR-MORREALE HF. Effects of polycystic ovary syndrome (PCOS), sex hormones, and obesity on circulating miRNA-21, miRNA-27b, miRNA-103, and miRNA-155 expression. J Clin Endocrinol Metab 2013; 98 : E1835-E1844. http://dx.doi.org/10.1210/jc.2013-2218

[11] MUZIK J. DL, BABJUK M., KUBASEK M., FINEK J., PETRUZELKA L. Uroweb - webový portál pro analýzu a vizualizaci epidemiologie, diagnostiky a léčby urologických malignit [online]. Masarykova univerzita, Brno, 2016. Accessed at http: //www.uroweb.cz, 05-June-2016

[12] KNOWLES MA. Molecular subtypes of bladder cancer: Jekyll and Hyde or chalk and cheese? Carcinogenesis 2006; 27: 361-373. http://dx.doi.org/10.1093/carcin/bgi310

[13] CATTO JW, MIAH S, OWEN HC, BRYANT H, MYERS K et al. Distinct microRNA alterations characterize high-and lowgrade bladder cancer. Cancer Res 2009; 69: 8472-8481. http:// dx.doi.org/10.1158/0008-5472.CAN-09-0744

[14] ABDOLLAH F, GANDAGLIA G, THURET R, SCHMITGES J, TIAN $Z$ et al. Incidence, survival and mortality rates of stage-specific bladder cancer in United States: a trend analysis. Cancer Epidemiol 2013; 37: 219-225. http://dx.doi. org/10.1016/j.canep.2013.02.002

[15] DUSEK LADISLAV MJ, KUBASEK MIROSLAV, KOPTIKOVA JANA, ZALOUDIK JAN, VYZULA ROSTISLAV. Epidemiologie zhoubných nádorů v České republice [online]. Masarykova univerzita, Brno, 2005. Accessed at http: //www. svod.cz, 05-June-2016

[16] YUN SJ, JEONG P, KIM WT, KIM TH, LEE YS et al. Cell-free microRNAs in urine as diagnostic and prognostic biomarkers of bladder cancer. Int J Oncol 2012; 41: 1871-1878.

[17] LIN T, DONG W, HUANG J, PAN Q, FAN X et al. MicroRNA143 as a tumor suppressor for bladder cancer. J Urol 2009; 181: 1372-1380. http://dx.doi.org/10.1016/j.juro.2008.10.149

[18] ZHANG D-Z, LAU K-M, CHAN ES, WANG G, SZETO C-C et al. Cell-free urinary microRNA-99a and microRNA-125b are diagnostic markers for the non-invasive screening of bladder cancer. PloS One 2014; 9: http://dx.doi.org/10.1371/ journal.pone.0100793

[19] SNOWDON J, BOAG S, FEILOTTER H, IZARD J, SIEMENS DR. A pilot study of urinary microRNA as a biomarker for urothelial cancer. Can Urol Assoc J 2013; 7: 28-32. http:// dx.doi.org/10.5489/cuaj.278

[20] ZHOU X, ZHANG X, YANG Y, LI Z, DU L et al. Urinary cell-free microRNA-106b as a novel biomarker for detection of bladder cancer. Med Oncol 2014; 31: 1-7. http://dx.doi. org/10.1007/s12032-014-0197-z

[21] KAN T, SATO F, ITO T, MATSUMURA N, DAVID S et al. The miR-106b-25 polycistron, activated by genomic amplification, functions as an oncogene by suppressing p21 and Bim. Gastroenterology 2009; 136: 1689-1700. http://dx.doi. org/10.1053/j.gastro.2009.02.002

[22] HUDSON RS, YI M, ESPOSITO D, GLYNN SA, STARKS AM et al. MicroRNA-106b-25 cluster expression is associ- ated with early disease recurrence and targets caspase- 7 and focal adhesion in human prostate cancer. Oncogene 2013; 32: 4139-4147. http://dx.doi.org/10.1038/onc.2012.424

[23] KIM SM, KANG HW, KIM WT, KIM Y-J, YUN SJ et al. Cell-free microRNA-214 from urine as a biomarker for non-muscle-invasive bladder cancer. Korean J Urol 2013; 54: 791-796. http://dx.doi.org/10.4111/kju.2013.54.11.791

[24] HANKE M, HOEFIG K, MERZ H, FELLER AC, KAUSCH I et al. A robust methodology to study urine microRNA as tumor marker: microRNA-126 and microRNA-182 are related to urinary bladder cancer. Urol Oncol 2010; 28: 655-661. http:// dx.doi.org/10.1016/j.urolonc.2009.01.027

[25] YAMADA Y, ENOKIDA H, KOJIMA S, KAWAKAMI K, CHIYOMARU $\mathrm{T}$ et al. MiR-96 and miR-183 detection in urine serve as potential tumor markers of urothelial carcinoma: correlation with stage and grade, and comparison with urinary cytology. Cancer Sci 2011; 102: 522-529. http:// dx.doi.org/10.1111/j.1349-7006.2010.01816.x

[26] BRISUDA A, PAZOURKOVA E, SOUKUP V, HORINEK A, HRBACEK J et al. Urinary Cell-Free DNA Quantification as Non-Invasive Biomarker in Patients with Bladder Cancer. Urol Int 2016; 96: 25-31. http://dx.doi.org/10.1159/000438828

[27] DWEEP H, GRETZ N, STICHT C. In: (Eds.), RNA Mapping, Springer, 2014, 289-305

[28] HUANG DW, SHERMAN BT, LEMPICKI RA. Systematic and integrative analysis of large gene lists using DAVID bioinformatics resources. Nat Protoc 2008; 4: 44-57. http://dx.doi. org/10.1038/nprot.2008.211

[29] HUANG DW, SHERMAN BT, LEMPICKI RA. Bioinformatics enrichment tools: paths toward the comprehensive functional analysis of large gene lists. Nucleic Acids Res 2009; 37: 1-13. http://dx.doi.org/10.1093/nar/gkn923

[30] LAMBA V, GHODKE-PURANIK Y, GUAN W, LAMBA JK. Identification of suitable reference genes for hepatic microRNA quantitation. BMC Res Notes 2014; 7: 129. http://dx.doi. org/10.1186/1756-0500-7-129

[31] WEBER JA, BAXTER DH, ZHANG S, HUANG DY, HUANG $\mathrm{KH}$ et al. The microRNA spectrum in 12 body fluids. Clin Chem 2010; 56: 1733-1741. http://dx.doi.org/10.1373/ clinchem.2010.147405

[32] RATERT N, MEYER H-A, JUNG M, MOLLENKOPF H-J, WAGNER I ET AL. Reference miRNAs for miRNAome analysis of urothelial carcinomas. PLoS One 2012; 7: e39309 http://dx.doi.org/10.1371/journal.pone.0039309

[33] JARRY J, SCHADENDORF D, GREENWOOD C, SPATZ A, VAN KEMPEN L. The validity of circulating microRNAs in oncology: five years of challenges and contradictions. Mol Oncol 2014; 8: 819-829. http://dx.doi.org/10.1016/j. molonc.2014.02.009

[34] TANG K, ZHOU H, XIAO H, ZENG J, GUAN W et al. A panel of eight-miRNA signature as a potential biomarker for predicting survival in bladder cancer. J Exp Clin Cancer Res 2015; 34: 53-53. http://dx.doi.org/10.1186/s13046-015-0167-0

[35] HUANG L, LUO J, CAI Q, PAN Q, ZENG H et al. MicroRNA-125b suppresses the development of bladder cancer by targeting E2F3. Int J Cancer 2011; 128: 1758-1769. http:// dx.doi.org/10.1002/ijc.25509 
[36] FENG Y, KANG Y, HE Y, LIU J, LIANG B et al. microRNA$99 \mathrm{a}$ acts as a tumor suppressor and is down-regulated in bladder cancer. BMC Urol 2014; 14: 50. http://dx.doi. org/10.1186/1471-2490-14-50

[37] CALIN GA, SEVIGNANI C, DUMITRU CD, HYSLOP T, NOCH E et al. Human microRNA genes are frequently located at fragile sites and genomic regions involved in cancers. Proc Natl Acad Sci U S A 2004; 101: 2999-3004. http://dx.doi. org/10.1073/pnas.0307323101

[38] BESARATINIA A, TOMMASI S. Genotoxicity of tobacco smoke-derived aromatic amines and bladder cancer: current state of knowledge and future research directions. FASEB J 2013; 27: 2090-2100. http://dx.doi.org/10.1096/ f. $12-227074$

[39] PIGNOT G, CIZERON-CLAIRAC G, VACHER S, SUSINI A, TOZLU S et al. microRNA expression profile in a large series of bladder tumors: Identification of a 3-miRNA signature associated with aggressiveness of muscle-invasive bladder cancer. Int J Cancer 2013; 132: 2479-2491. http://dx.doi.org/10.1002/ ijc. 27949

[40] YOSHINO H, CHIYOMARU T, ENOKIDA H, KAWAKAMI K, TATARANO $S$ et al. The tumour-suppressive function of miR-1 and miR-133a targeting TAGLN2 in bladder cancer. Br J Cancer 2011; 104: 808-818. http://dx.doi.org/10.1038/bjc.2011.23
[41] WSZOLEK MF, RIEGER-CHRIST KM, KENNEY PA, GOULD JJ, NETO BS et al. A MicroRNA expression profile defining the invasive bladder tumor phenotype. Urol Oncol 2011; 29: 794-801. e791.

[42] MAHDAVINEZHAD A, MOUSAVIBAHAR SH, POOROLAJAL J, YADEGARAZARI R, JAFARI M ET AL. Association between Tissue miR-141, miR-200c and miR-30b and Bladder Cancer: A Matched Case-Control Study. Urol J 2015; 12: 2010-2013.

[43] MAHDAVINEZHAD A, MOUSAVI-BAHAR SH, POOROLAJAL J, YADEGARAZARI R, JAFARI M ET AL. Evaluation of miR-141, miR-200c, miR-30b Expression and Clinicopathological Features of Bladder Cancer. Int J Mol Cell Med 2015; 4: 32-39.

[44] WEI S, BING Z, YAO Y, MASTER SR, GUPTA P. Higher Expression of miR-182 in Cytology Specimens of High-Grade Urothelial Cell Carcinoma: A Potential Diagnostic Marker. Acta Cytol 2015; 59: 103-106. http://dx.doi. org/10.1159/000371507

[45] ZHAO B-S, LIU S-G, WANG T-Y, JI Y-H, QI B et al. Screening of microRNA in patients with esophageal cancer at same tumor node metastasis stage with different prognoses. Asian Pac J Cancer Prev 2013; 14: 139-143. http://dx.doi.org/10.7314/ APJCP.2013.14.1.139 


\begin{tabular}{|c|c|c|c|c|}
\hline \multirow{2}{*}{ Examined matarial } & \multirow{2}{*}{ Normalisation } & \multicolumn{2}{|c|}{ Selected miRNAs } & \multirow{2}{*}{ Reference } \\
\hline & & Down regulated & Up regulated & \\
\hline \multirow[t]{4}{*}{ Tissue } & U6 & miR-143 & & Lin [17] \\
\hline & & miR-145 & & \\
\hline & & miR-125b & & \\
\hline & & miR-199b & & \\
\hline \multirow[t]{5}{*}{ Tissue } & U6 & miR-145 & $\operatorname{miR}-141-3 p$ & Tang [34] \\
\hline & & $\operatorname{miR}-125 b$ & $\operatorname{miR}-200 c-3 p$ & \\
\hline & & miR-199a & $\operatorname{miR}-21-5 p$ & \\
\hline & & let-7c & & \\
\hline & & $\operatorname{miR}-99 a$ & & \\
\hline \multirow[t]{7}{*}{ Tissue } & RNU44, U6B & miR-1 & $\operatorname{miR}-200 b$ & Pignot [39] \\
\hline & & $\operatorname{miR}-133 \mathrm{a} / \mathrm{b}$ & miR-182 & \\
\hline & & miR-145 & miR-614 & \\
\hline & & miR-143 & $\operatorname{miR}-1231$ & \\
\hline & & miR-204 & miR-654-3p & \\
\hline & & & miR-921 & \\
\hline & & & $\operatorname{miR}-1281$ & \\
\hline \multirow[t]{17}{*}{ Tissue } & RNU48, U6 & miR-133a & & Yoshino [40] \\
\hline & & miR-204 & & \\
\hline & & miR-1 & & \\
\hline & & miR-139-5p & & \\
\hline & & $\operatorname{miR}-370$ & & \\
\hline & & $\operatorname{miR}-133 b$ & & \\
\hline & & $\operatorname{miR}-574-3 p$ & & \\
\hline & & $\operatorname{miR}-376 \mathrm{c}$ & & \\
\hline & & miR-214 & & \\
\hline & & let-7c & & \\
\hline & & $\operatorname{miR}-140-3 p$ & & \\
\hline & & $\operatorname{miR}-134$ & & \\
\hline & & miR-411 & & \\
\hline & & miR-218 & & \\
\hline & & miR-196b & & \\
\hline & & miR-186 & & \\
\hline & & miR-320 & & \\
\hline \multirow[t]{3}{*}{ Tissue } & 5s rRNA & & miR-30b & Mahdavinezhad $[42,43]$ \\
\hline & & & miR-141 & \\
\hline & & & miR-200c & \\
\hline \multirow{9}{*}{$\begin{array}{l}\text { Tissue: invasive } \\
\text { compared to } \\
\text { noninvasive tumors }\end{array}$} & miR-222 & miR-30b & miR-99a & Wszolek [41] \\
\hline & & miR-31 & & \\
\hline & & miR-141 & & \\
\hline & & miR-200a & & \\
\hline & & miR-200b & & \\
\hline & & miR-200c & & \\
\hline & & miR-429 & & \\
\hline & & miR-205 & & \\
\hline & & $\operatorname{miR}-21$ & & \\
\hline Tissue & U6 & miR-99a & & Feng [36] \\
\hline Tissue & RNU6B & miR-1 & miR-16 & Zhang [18] \\
\hline & & miR-99a & miR-96 & \\
\hline & & miR-125b & $\operatorname{miR}-183$ & \\
\hline & & miR-133a & & \\
\hline & & miR-133b & & \\
\hline & & miR-143 & & \\
\hline & & miR-1207-5p & & \\
\hline Plasma & U6 & miR-99a & & Feng [36] \\
\hline Whole urine & $\operatorname{miR}-152$ & & miR-126 & Hanke [24] \\
\hline & & & miR-182 & \\
\hline Whole urine & RNU6B & & miR-96 & Yamada [25] \\
\hline & & & miR-183 & \\
\hline Whole urine, bladder & quantity was & & miR-182 & Wei [44] \\
\hline and renal washs & acquired based & & & \\
\hline Urine supernatant & & miR-99a & miR-16 & Zhang [18] \\
\hline & & $\operatorname{miR}-125 b$ & miR-96 & \\
\hline & & $\operatorname{miR}-133 b$ & $\operatorname{miR}-183$ & \\
\hline & & miR-143 & & \\
\hline Urine supernatant & U6 & miR-125b & & Snowdon [19] \\
\hline Urine supernatant & U6 & miR-145 & & Yun [16] \\
\hline & & miR-200a & & \\
\hline Urine supernatant & U6 & & miR-106b & Zhou [20] \\
\hline & & & miR-93 & \\
\hline & & & $\operatorname{miR}-25$ & \\
\hline Urine supernatant & U6 & & miR-214 & Kim [23] \\
\hline
\end{tabular}

